\section{Branching of Chrysanthemum Cultivars Varies with Season, Temperature, and Photosynthetic Photon Flux}

\author{
Richard K. Schoellhorn, James E. Barrett, and Terril A. Nell \\ Department of Environmental Horticulture, Institute of Food and Agricultural \\ Sciences, University of Florida, Gainesville, FL 32611
}

Additional index words. Dendranthema $\times$ grandiflorum, apical dominance, lateral branch development, cultivar variation, seasonal effects, root-zone temperature, PPF

\begin{abstract}
Effects of photosynthetic photon flux (PPF) and temperature on quantitative axillary budbreak and elongation of pinched chrysanthemum [Dendranthema $\times$ grandiflorum (Ramat.) Kitamura] plants were studied in three experiments. In Expt. 1, 12 commercial cultivars were compared under fall and spring environmental conditions. Spring increases in lateral shoot counts were attributable to increased PPF and air temperature. Cultivars varied from 0 to 12 lateral branches per pinched plant and by as much as $60 \%$ between seasons. There was a linear relationship between lateral branches $>5 \mathrm{~cm}$ at 3 weeks after pinching and final branch count $\left(\mathrm{y}=0.407+0.914(\mathrm{x}), r^{2}=0.92\right)$. In Expt. 2, air was at 20 or $25 \mathrm{C}$ and the root zone was maintained at 5,0 , or $-5 \mathrm{C}$ relative to air temperature. With air at $20 \mathrm{C}$, lateral branch counts $(3$ weeks after pinch) declined by $\leq 50 \%$ with the medium at $15 \mathrm{C}$ relative to $25 \mathrm{C}$. At $25 \mathrm{C}$, lateral branch count was lower with medium at $30 \mathrm{C}$ than at $20 \mathrm{C}$. Cultivars differed in their response to the treatments. Experiment 3 compared the interactions among temperature, PPF, and cultivar on lateral branch count. Depending on cultivar, the count increased the higher the PPF between 400 and $1400 \mu \mathrm{mol} \cdot \mathrm{m}^{-2} \cdot \mathrm{s}^{-1}$. Air temperature had no effect on lateral branch count. PPF had a stronger effect on lateral branch count than air temperature, and cultivars differed in their response.
\end{abstract}

Branching response of chrysanthemum is controlled by genotype and environmental stimuli (Hicklenton, 1985; Moe, 1988). Growth rate models for chrysanthemum (Karlsson et al., 1988) and the effects of environmental stimuli on chrysanthemum physiology (Acock et al., 1979; de Lint and Heij, 1987; Heins and Wilkins, 1979; Nell et al., 1981) have been reported. Specifically, the influence of temperature (Moe and Heins, 1990) and light on vegetative growth (Heins et al., 1986; Hicklenton, 1985; Karlsson et al., 1989a, 1989b; Stephanis and Langhans, 1982) and flower development (Cockshull, 1976; Parvups and Butler, 1982; Whealy et al., 1987) have been evaluated. These reports focus on the qualitative aspects of growth and metabolism but do not provide quantitative information on lateral shoot development under various environmental conditions. Our research was conducted to determine the role of season, temperature, and photosynthetic photon flux (PPF) level on quantitative budbreak and branch elongation in various chrysanthemum cultivars.

\section{Materials and Methods}

Cultivar and seasonal trials (Expt. 1). Unrooted cuttings of 12 chrysanthemum cul-

Received for publication 7 Apr. 1995. Accepted for publication 28 Aug. 1995. The cost of publishing this paper was defrayed in part by the payment of page charges. Under postal regulations, this paper therefore must be hereby marked advertisement solely to indicate this fact. tivars (Table 1) were obtained from commercial sources, dipped for $10 \mathrm{sec}$ in a solution of $1.2 \mathrm{~g}$ butanidioic acid mono(2-2 dimethylhydrazide) (daminozide)/liter, and stored at $7 \mathrm{C}$ for $24 \mathrm{~h}$. The cuttings were planted in pots $10 \mathrm{~cm}$ in diameter (0.64 liter) using Vergro Klay mix (Verlite Co., Tampa, Fla.), placed under intermittent mist, and maintained under long-day photoperiod by lighting from 2200 to $0200 \mathrm{HR}$. After 14 days, plants were spaced nine per square meter in a glass greenhouse with fan and pad cooling. A soft pinch removed the apical meristem and all leaves smaller than $1 \mathrm{~cm}^{2}$ in surface area. Remaining leaves were counted to determine potential lateral buds; short-day $(8.50 \mathrm{~h})$ photoperiods were initiated at time of pinch. From time of placement in the greenhouse, all plants were fertilized daily with a water-soluble fertilizer $(20 \mathrm{~N}-4.7 \mathrm{P}-16.6 \mathrm{~K})$ at $300 \mathrm{mg} \mathrm{N} / \mathrm{liter}$. Three weeks after pinching, all plants received a foliar spray of daminozide at $5.0 \mathrm{~g} \cdot \mathrm{liter}^{-1}$. The experiment was conducted twice ( 2 Nov. 1990 and 14 Apr. 1991). During the fall trial, the average day maximum was $25 \mathrm{C}$ and average night minimum was $18 \mathrm{C}$. Relative humidity (RH) averaged $90 \%$ day and $65 \%$ night, and daily average maximum PPF was 840 $\mu \mathrm{mol} \cdot \mathrm{m}^{-2} \cdot \mathrm{s}^{-1}$. During the spring trials, the average day maximum was $29 \mathrm{C}$ and the night minimum was $24 \mathrm{C}$. $\mathrm{RH}$ averaged $75 \%$ days and $100 \%$ nights, and daily average maximum $\mathrm{PPF}$ was $950 \mu \mathrm{mol} \cdot \mathrm{m}^{-2} \cdot \mathrm{s}^{-1}$.

Two weeks after pinch, all lateral branches $\geq 3 \mathrm{~cm}$ long were counted, and at 3 weeks, lateral branches $\geq 5 \mathrm{~cm}$ long were counted. When the first fully open flower developed on each plant, the number of lateral branches was determined in three ways: 1 ) with buds showing color, 2) $\geq 75 \%$ the length of first flowering lateral, and 3) plants that developed a fully open flower within 1 week of the first flowering lateral. A flower was considered fully open when the petals reflexed to a horizontal plane (Karlsson et al., 1989a; Nell and Barrett, 1991). Data from fall and spring trials were combined, and regression analysis was conducted between final measurements and lateral branches measured at 2 and 3 weeks after pinching.
Table 1. Number of lateral branches produced on 12 chrysanthemum cultivars in Fall 1990 (mean temperature $25 \mathrm{C}$ day/18C night, relative humidity $90 \%$ day and $65 \%$ night, photosynthetic flux 840 $\mu \mathrm{mol} \cdot \mathrm{m}^{-2} \cdot \mathrm{s}^{-1}$ ) and Spring 1991 (mean temperature $29 \mathrm{C}$ day $/ 24 \mathrm{C}$ night, relative humidity $75 \%$ day and $100 \%$ night, photosynthetic photon flux $950 \mu \mathrm{mol} \cdot \mathrm{m}^{-2} \cdot \mathrm{s}^{-1}$ ) as judged by final evaluation methods (Expt. 1).

\begin{tabular}{|c|c|c|c|c|c|c|}
\hline \multirow[b]{3}{*}{ Cultivar } & \multicolumn{3}{|c|}{ Fall 1990} & \multicolumn{3}{|c|}{ Spring 1991} \\
\hline & \multicolumn{3}{|c|}{ Evaluation methods ${ }^{z}$} & \multicolumn{3}{|c|}{ Evaluation methods ${ }^{z}$} \\
\hline & $\begin{array}{l}\text { Bud } \\
\text { color }\end{array}$ & $\begin{array}{l}\text { Shoot } \\
\text { length }\end{array}$ & $\begin{array}{c}\text { Open } \\
\text { flower }\end{array}$ & $\begin{array}{l}\text { Bud } \\
\text { color }\end{array}$ & $\begin{array}{l}\text { Shoot } \\
\text { length }\end{array}$ & $\begin{array}{c}\text { Open } \\
\text { flower }\end{array}$ \\
\hline \multicolumn{7}{|c|}{ Potted production } \\
\hline Boaldi & 6.0 & 7.0 & 5.8 & 6.7 & 6.8 & 6.6 \\
\hline Bright Golden Anne & 4.1 & 4.5 & 3.2 & 4.8 & 5.2 & 4.8 \\
\hline Davis & 5.7 & 7.7 & 6.4 & 6.7 & 8.1 & 7.0 \\
\hline Limelight & 3.6 & 3.6 & 3.3 & 4.6 & 4.6 & 4.7 \\
\hline Royal Trophy & 4.5 & 5.0 & 3.8 & 4.3 & 4.7 & 4.3 \\
\hline Tara & 4.5 & 5.6 & 4.7 & 6.1 & 7.1 & 5.9 \\
\hline Theme & 6.2 & 6.4 & 6.0 & 6.6 & 6.7 & 6.7 \\
\hline Yellow Ovaro & 5.2 & 5.5 & 5.0 & 5.8 & 6.2 & 5.8 \\
\hline Yellow Torch & 4.3 & 4.8 & 4.2 & 5.6 & 6.5 & 5.6 \\
\hline \multicolumn{7}{|c|}{ Cut production } \\
\hline Improved Mefo & 1.2 & 1.2 & 1.2 & 3.6 & 4.7 & 3.6 \\
\hline Fuji Mefo & 1.7 & 1.7 & 1.7 & 3.2 & 4.5 & 3.3 \\
\hline Nimba & 3.2 & 5.9 & 4.3 & 3.8 & 4.8 & 4.1 \\
\hline \multicolumn{7}{|l|}{ HSD } \\
\hline 0.05 & 1.15 & 1.18 & 1.14 & 1.71 & 1.87 & 1.83 \\
\hline 0.01 & 1.32 & 1.35 & 1.30 & 1.96 & 2.14 & 2.10 \\
\hline
\end{tabular}

${ }^{2}$ Evaluation methods: bud color, branches showing color when first flower is fully open; length, branches $75 \%$ length of lateral with first open flower; open flower, branches in flower within 1 week of first open flower. 
Root-zone and air temperature relationships (Expt. 2). Two growth chambers were used to maintain air temperatures at 20 or $25 \mathrm{C}$. PPF was $900 \mu \mathrm{mol} \cdot \mathrm{m}^{-2} \cdot \mathrm{s}^{-1}$ at canopy level under high-pressure sodium lights for $12 \mathrm{~h}$ daily. Incandescent flood lamps provided 300 $\mu \mathrm{mol} \cdot \mathrm{m}^{-2} \cdot \mathrm{s}^{-1}$ from 2200 to $0200 \mathrm{HR}$ to maintain a long-day photoperiod.

Root-zone temperature control units were constructed from polyvinylchloride piping. Pipe $20 \mathrm{~cm}$ in diameter $\times 30 \mathrm{~cm}$ long formed the outer shell of the unit, and inner walls were formed by a pipe $10 \mathrm{~cm}$ in diameter $\times 30 \mathrm{~cm}$ long. The top and bottom of each unit was sealed with acrylinitrile butadiene styrene plastic. Each unit was fitted with input and output valves and connected to a recirculating water system. Chambers were lined with polyethylene and filled with Vergro Klay mix.

With air at 20C, the medium was maintained at $15 \pm 0.5 \mathrm{C}, 20 \pm 2 \mathrm{C}$, or $25 \pm 2 \mathrm{C}$. With air at $25 \mathrm{C}$, medium was $20 \pm 2 \mathrm{C}, 25 \pm 2 \mathrm{C}$, or $30 \pm 0.5 \mathrm{C}$. Thus, medium temperatures were 5,0 , and $-5 \mathrm{C}$ in relation to air temperature.

In each chamber, 24 root-zone temperature control units were randomized in a split-plot design, with air temperature as the main effect and root-zone temperature as the subplot. The treatments were replicated three times, eight plants per experimental unit in individual rootzone temperature chambers, and tested using analysis of variance. Planting dates for 'Limelight' were 6 Dec. 1991 and 11 Jan. and 6 Mar. 1992 and for 'Tara', 7 May, 15 June, and 26 Aug. 1992. Cultural procedures were the same as those described in Expt. 1. At pinch, all nodes were counted, and at 3 weeks after pinch, all lateral branches $\geq 5 \mathrm{~cm}$ long were measured. 'Limelight' and 'Tara' were in separate experiments.

PPF and temperature effects (Expt. 3). A third experiment was designed to examine the interactions between cultivar, PPF level, and production temperature. 'Tara', 'Limelight', and 'Improved Mefo' plants were grown under three PPF levels and two temperature regimes. Average daily maximum PPF levels in greenhouses were 1400 (ambient), 780, and $400 \mu \mathrm{mol} \cdot \mathrm{m}^{-2} \cdot \mathrm{s}^{-1}$. PPF was controlled by adding one and two layers of $30 \%$ shadecloth. Cycles were maintained at $23 \mathrm{C}$ day/17C night or $29 \mathrm{C}$ day/23C night. A long-day photoperiod was provided by lighting from 2200 to $0200 \mathrm{HR}$ with incandescent lamps. Branching was measured using the same techniques as previously stated. A split-split plot design, with air temperature as the main effect and PPF as subplot, was analyzed using analysis of variance and mean separation at final analysis. The experiment was replicated four times with five plants per experimental unit. Uniformly rooted cuttings were used and cultural procedures were as outlined in Expt. 1. Planting was on 8 Feb., 15 Feb., 17 Mar., and 24 Mar. 1992.

\section{Results and Discussion}

Cultivar and seasonal effects on lateral branch count (Expt. 1). Cultivars used in potted plant production, such as 'Tara', 'Davis', 'Boaldi', and 'Theme', produced about twice as many lateral branches as 'Nimba', 'Fuji Mefo', and 'Improved Mefo', which are used in cut-flower production (Table 1).

Some cultivars showed a stronger response to seasonal effects than others. 'Tara' is known in commercial production for more vigorous growth at higher production temperatures, which was expressed as increased branching in the spring over the fall trial. Other cultivars with a large increase in spring relative to fall lateral count were 'Davis', 'Fuji Mefo', and 'Improved Mefo'. 'Royal Trophy' and 'Nimba' produced fewer laterals under spring growing conditions. We attribute the increase in branch number seen in the Mefo cultivars more to stock plant culture than to conditions under which plants were produced. 'Mefo' cuttings, taken from stock plants grown under high temperatures in Florida, have a higher percentage of lateral buds that fail to elongate (personal observations). Cuttings used in the fall trial came from Florida-grown stock plants, but cuttings for the spring trial came from California, where they were produced under cooler conditions. This "preconditioning" response has been documented in earlier re- search on stock plant culture (Karlsson et al., 1989a) and its effects on cutting performance in chrysanthemum (Borowski et al., 1981; Moe, 1988). Faust and Heins's (1993) recent research on chrysanthemum stock plants showed that night temperature did not affect lateral count.

Fall-grown plants generally received lower total PPF, temperatures, and $\mathrm{RH}$ than plants in the spring trial. While average daily maximum PPF for fall, measured under clear skies, was not greatly different from spring levels, the shorter daylength and fewer clear days during this trial reduced total light relative to the spring trial. The increase in number of lateral branches formed is a result of differences in these factors. Acock (1979) reported a positive correlation for stem length and leaf size in Dendranthema with higher air temperatures, but no previous research correlates high temperatures with increased lateral budbreak. PPF (Holcomb et al., 1988) and RH (Hicklenton, 1985) also have been proposed as factors contributing to the release of lateral buds from apical inhibition. Earlier work with chrysanthemum by these authors showed that increases
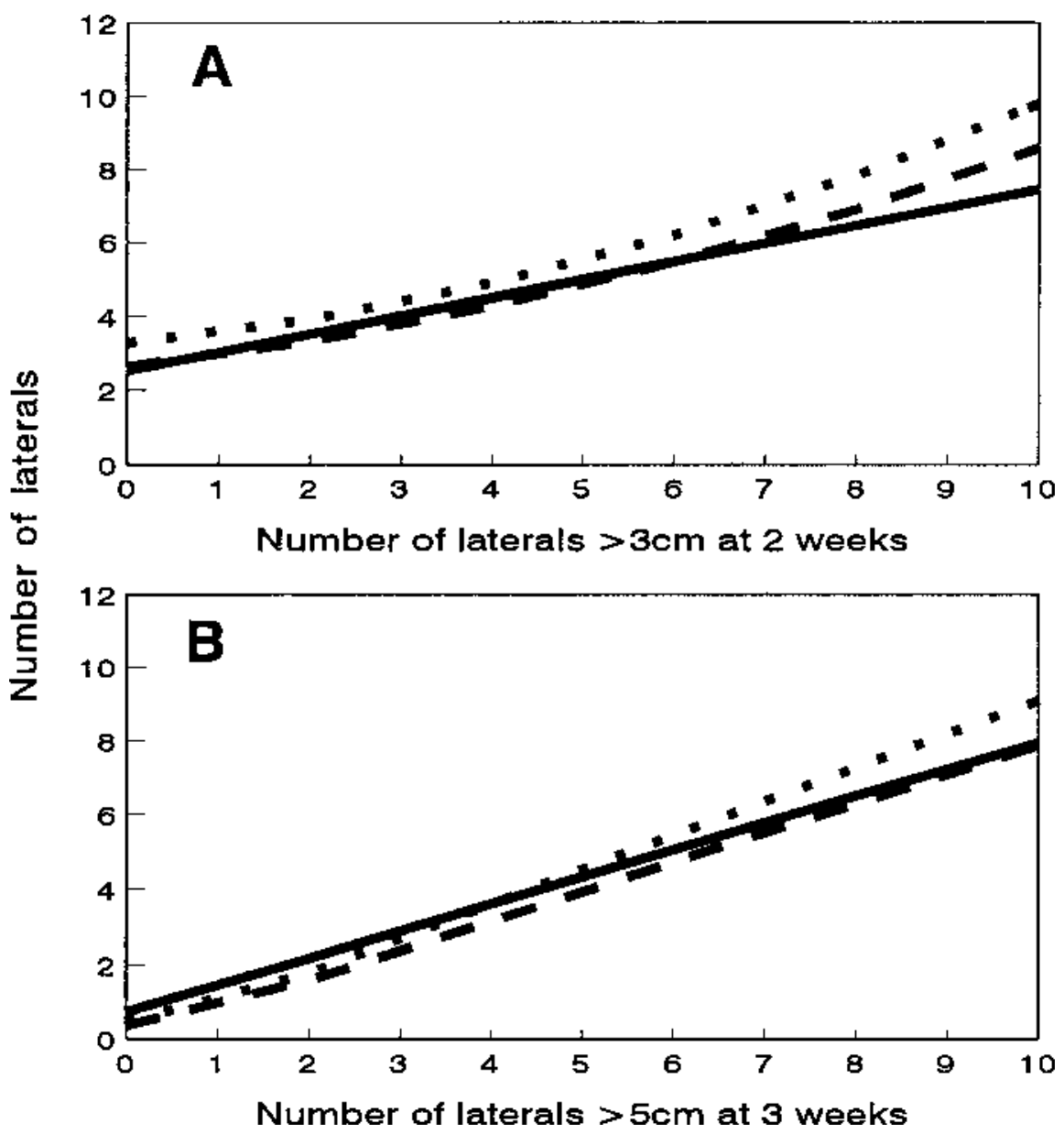

Fig. 1. Regression analysis of lateral branches (A) $\geq 3 \mathrm{~cm}$ at 2 weeks after pinch and $(\mathbf{B}) \geq 5 \mathrm{~cm}$ at 3 weeks after pinch, with lateral branches at final evaluation. Three final evaluation methods were used to determine relationship of early laterals to $(-1)$ lateral branches with buds showing color at first open flower $\left.\left[(\mathbf{A}) \mathrm{y}=2.528+0.491(\mathrm{x}), r^{2}=0.55,(\mathbf{B}) \mathrm{y}=0.723+0.722(\mathrm{x}), r^{2}=0.70\right],(----) 2\right)$ lateral branches $\geq 75 \%$ length of first flowering lateral $\left[(\mathbf{A}) \mathrm{y}=3.278+0.239(\mathrm{x})+0.041\left(\mathrm{x}^{2}\right), r^{2}=0.65,(\mathbf{B}) \mathrm{y}=0.407+\right.$ $\left.0.914(\mathrm{x}), r^{2}=0.92\right]$, and (- 3) lateral branches that form an open flower within 1 week of first flower $\left[(\mathbf{A}) \mathrm{y}=2.641+0.282(\mathrm{x})+0.031\left(\mathrm{x}^{2}\right), r^{2}=0.64,(\mathbf{B}) \mathrm{y}=0.402+0.785(\mathrm{x}), r^{2}=0.78\right]$. Spring and fall trials for 12 cultivars are represented $(n=144)($ Expt. 1$)$. 
in PPF lead to an increase in $\mathrm{CO}_{2}$ assimilation. An increase in photosynthate would enable more lateral buds to elongate by reducing competition for substrates. Hicklenton (1985) also proposed higher $\mathrm{RH}$ to increase lateral budbreak by reducing transpiration losses and affecting the water potential within the lateral bud. The higher RH levels in the spring trial may have affected lateral budbreak in this manner.

The correlation between data taken at time of flowering and measurements taken at 2 weeks after pinch indicated linear and quadratic relationships between the number of lateral branches at 2 weeks and final branching, depending on criteria of measurement (Fig. 1). The strongest correlation was with final lateral branches $\geq 75 \%$ of the length of the first flowering lateral $\left(r^{2}=0.65\right)$. By 3 weeks, only linear relationships existed between the number of lateral branches $\geq 5 \mathrm{~cm}$ at 3 weeks and the number of lateral branches in each final evaluation method; all had higher $r^{2}$ values than for 2 weeks (Fig. 1). Again, the strongest correlation was lateral branches $75 \%$ of the length of the first flowering lateral $\left(r^{2}=\right.$ 0.92 ).

The correlations based on lateral branches $\geq 3 \mathrm{~cm}$ at week 2 are weaker than those taken a week later because the developing lateral branches of 'Royal Trophy' and 'Yellow Torch' were too short to be counted at week 2 but were $\geq 5 \mathrm{~cm}$ at week 3 . This technique appears to be a reliable measure of final lateral count for many cultivars, remaining accurate under changing seasonal conditions.

Root-zone and air temperature relationships (Expt. 2). There was a significant lateral count between medium $\times$ air temperatures interaction for 'Limelight' and 'Tara' (Fig. 2).
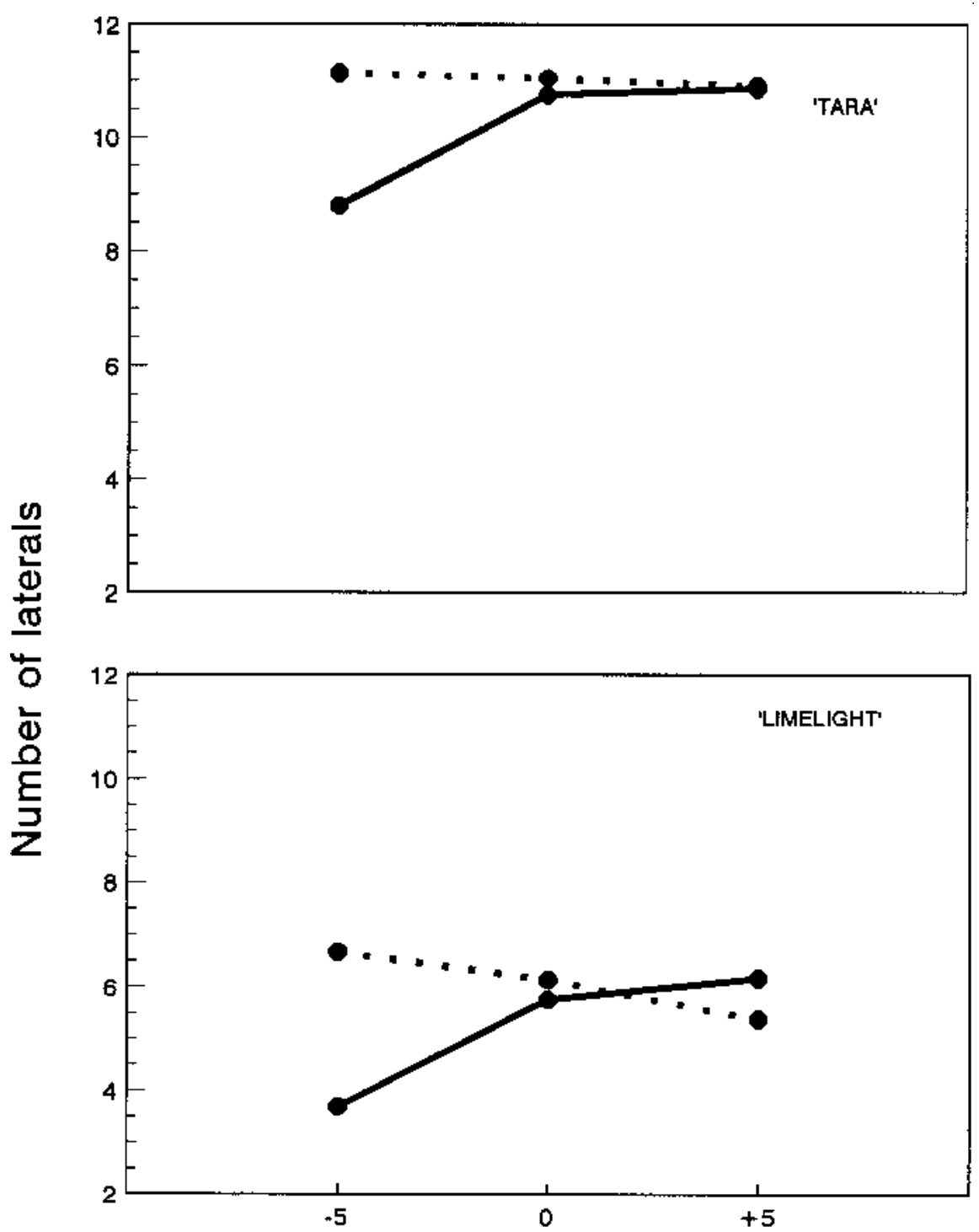

Root temperature in relation to air temperature

Fig. 2. Number of lateral branches on 'Limelight' and 'Tara' chrysanthemum at air-medium temperature differentials maintained at two air temperatures. With air at $(-), 20 \mathrm{C}$ points on line indicate lateral branches formed at air and medium temperatures of $20 \mathrm{C} / 15 \mathrm{C}, 20 \mathrm{C} / 20 \mathrm{C}$, and $20 \mathrm{C} / 25 \mathrm{C}$. With air at (-1) $25 \mathrm{C}$, points indicate number of lateral branches formed at 25C/20C, 25C/25C, and 25C/30C. For 'Tara', $\mathrm{HSD}_{0.01}=1.27$ and $\mathrm{HSD}_{0.05}=1.49$, and for 'Limelight', $\mathrm{HSD}_{0.01}=0.93$ and $\mathrm{HSD}_{0.05}=1.10$. (Expt. 2).

'Tara' produced more lateral branches than 'Limelight' under all treatments at either air temperature. Both cultivars produced fewer lateral branches with air at $20 \mathrm{C}$ and medium at $15 \mathrm{C}$ and showed a similar increase in lateral count at the higher medium temperatures. With air at $25 \mathrm{C}$ and medium at 30C, 'Limelight' lateral formation was reduced compared to medium at 20C. Conversely, with air at 20C, lateral formation was enhanced at the same air-medium differential. 'Tara' showed less sensitivity to medium temperatures when air was at $25 \mathrm{C}$, with little change in lateral count across treatments. As stated earlier, 'Tara' grows vigorously at higher temperatures; apparently only the $20 \mathrm{C}$ air-15C medium regime was low enough to reduce budbreak.

Brown and Ormrod (1980) found that with air at $16 \mathrm{C}$, medium heated to $25 \mathrm{C}$ reduced internode length and leaf area of chrysanthemum compared to plants grown with a 20C root zone. Their findings also showed that root zone warming had no beneficial effects with air $>21 \mathrm{C}$ and became detrimental if continued through the initiation of the short-day photoperiod. For 'Limelight', the $30 \mathrm{C}$ root zone reduced lateral production at $25 \mathrm{C}$ air. For 'Tara', however, these temperatures had no significant effect on lateral count. The decrease in lateral count with medium at $30 \mathrm{C}$ may have been the result of an increase in leaf diffusive resistance, induced by stomatal closure. In work with Acer rubrum L. (Graves et al., 1989), plants grown with roots at 36C showed increased leaf diffusive resistance and a decrease in shoot water potential compared to plants with roots grown at $24 \mathrm{C}$. Graves et al. (1991) found a similar response to elevated medium temperatures in work on Ailanthus altissima (Mill) Swingle. Graves hypothesized that the reduced root size commonly seen at elevated medium temperature could affect shoot water potential by decreasing xylary element diameter and increasing the amount of secondary cell wall materials, such as suberin. These changes in root cell structure would affect water movement and translocation of nutrients to the shoot.

The decrease in lateral count with $20 \mathrm{C}$ air$15 \mathrm{C}$ medium may be the result of a drop in leaf diffusive conductance and shoot water potential. In work with wheat (Triticum aestivum $\mathrm{L}$. var. Chisholm) (Al-Hamdani et al., 1990) at medium temperatures of 3 and $23 \mathrm{C}$, plants grown at $3 \mathrm{C}$ exhibited lower $\mathrm{CO}_{2}$ assimilation

Table 2. Analysis of variance for the effects of photosynthetic photon flux (PPF), temperature (T), and cultivar (C) on lateral count for 'Limelight', 'Improved Mefo', and 'Tara' chrysanthemums (Expt. 3).

\begin{tabular}{lc}
\hline \hline $\begin{array}{l}\text { Main effects and } \\
\text { interactions }\end{array}$ & $\begin{array}{c}\text { Lateral } \\
\text { count }\end{array}$ \\
\hline $\mathrm{PPF}$ & 0.0001 \\
$\mathrm{~T}$ & $\mathrm{NS}$ \\
$\mathrm{C}$ & 0.0001 \\
$\mathrm{PPF} \times \mathrm{T}$ & $\mathrm{NS}$ \\
$\mathrm{PPF} \times \mathrm{C}$ & 0.0001 \\
$\mathrm{C} \times \mathrm{T}$ & $\mathrm{NS}$ \\
$\mathrm{PPF} \times \mathrm{C} \times \mathrm{T}$ & $\mathrm{NS}$ \\
\hline
\end{tabular}

${ }^{\mathrm{N}}$ Nonsignificant at $P=0.05$. 
and leaf conductance, and had a lower internal $\mathrm{CO}_{2}$ concentration. Starches and sugars accumulated in the leaves as a result of decreased translocation at 3C. The increased root diameter of plants grown at suboptimal medium temperatures and changes within the cell membranes of the root also may affect water and nutrient translocation.

More lateral branches were produced with 25C air-20C medium than at 20C air-20C medium (Fig. 1). This difference may be due to the enhancement of leaf and shoot expansion rates by higher shoot temperatures. Increased shoot elongation and leaf expansion with increasing air temperatures has been reported in earlier work on chrysanthemum (Barrett et al., 1978; de Lint and Heij, 1987; Tsujita et al., 1981). Shoot length was reported to be a direct function of air temperature, independent of prevailing PPF; however, rootzone temperatures were not measured (Karlsson et al., 1989b). 'Bright Golden Anne' produced four to five more leaves at $26 \mathrm{C}$ than at $14 \mathrm{C}$ whether PPF level was 501 or 1520 $\mu \mathrm{mol} \cdot \mathrm{m}^{-2} \cdot \mathrm{s}^{-1}$, indicating that leaf expansion rates were a function of temperature not PPF (Heins et al., 1986). Acock (1979) also attributed leaf expansion rate to air temperature.

Previous research with chrysanthemums at various root-zone temperatures focused on methods of maintaining optimal plant growth under suboptimal air temperature (Barrett et al., 1978; Brown and Ormrod, 1979; Tsujita et al., 1981) but not on root-zone temperature effects on lateral development. These studies showed that vigorous lateral development depended on the relationship between air and medium temperatures. Sub- or supra-optimal root-zone temperature may ameliorate the effects of air temperature on lateral growth or accentuate these effects. This response varies among cultivars, with 'Limelight' more responsive to root-zone temperature than 'Tara'.

PPF and temperature effects (Expt. 3). $\mathrm{PPF}$, cultivar, and their interaction had a significant effect on lateral count, but temperature had no effect (Table 2). With temperature pooled, all cultivars showed an increase in lateral number as PPF increased (Fig. 3). However, lateral count in 'Tara' was more responsive to PPF than either 'Limelight' or 'Improved Mefo'. The more vigorous growth habit of 'Tara' also was apparent at all PPF levels, with lateral counts higher than the other cultivars. Acock et al. (1979) also reported an increase in lateral branch count at higher PPF and attributed improved growth to increased $\mathrm{CO}_{2}$ assimilation. In our study, differences in lateral count may reflect breeding selection or possibly differences in dry-matter partitioning between cultivars. The light intensity at the leaf surface affects photo-degradation of auxin levels in the tissue. At high PPF, auxin deterioration is increased, while at low PPF, high auxin levels inhibit budbreak (Moe and Heins, 1990).

\section{Conclusions}

These three experiments indicate that temperature, $\mathrm{PPF}$, and cultivar affect lateral branch development in chrysanthemum after pinching. The increases in air temperature and PPF under spring growing conditions led to increases in lateral counts for most cultivars. The relationship between root-zone temperature and air temperature also affects lateral branch development. A cool root zone can partially offset the effects of high air temperature. Medium at $15 \mathrm{C}$ inhibited lateral bud-

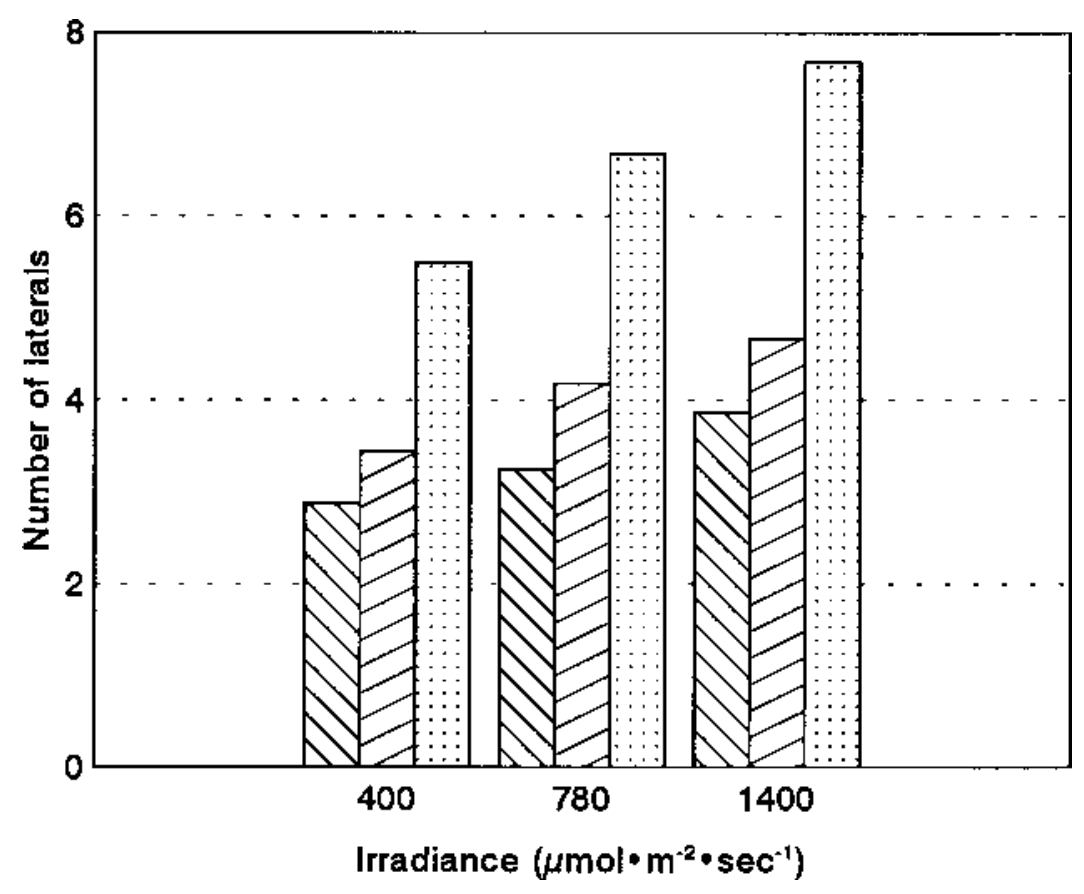

Fig. 3. Photosynthetic photon flux $(\mathrm{PPF}) \times$ cultivar interaction, pooled across temperature, on number of lateral branches $\geq 5 \mathrm{~cm}$ measured at 3 weeks after pinch. Cultivars shown are $(\mathbb{\nabla})$ 'Limelight', (口) 'Improved Mefo', and ( $\square$ ) 'Tara'. $\mathrm{HSD}_{0.05}=1.49$ and $\mathrm{HSD}_{0.01}=1.79$ (Expt. 3). break for both cultivars tested, a 30C medium also inhibited budbreak in 'Limelight' but had no significant effect on lateral count in 'Tara'. Finally, when comparing air temperature and PPF effects on lateral branching, only PPF and cultivar interacted significantly to affect lateral branch count per plant. Increased PPF led to development of more lateral branches but more so for 'Tara' than the other cultivars tested. The temperature ranges used in the final study had no effect on lateral branch count. This work indicates that for best lateral branch production, the commercial chrysanthemum producer should avoid extremes in medium temperature and maximize available PPF during all phases of growth before pinch.

\section{Literature Cited}

Acock, B., D.A. Charles-Edwards, and S. Sawyer. 1979. Growth response of a chrysanthemum crop to the environment. III. Effects of radiation and temperature on dry matter partitioning and photosynthesis. Ann. Bot. 43:290-299.

Al-Hamdani, S.H., G.W. Todd, and D.A. Francko. 1990. Response of wheat growth and $\mathrm{CO}_{2}$ assimilation to altering root-zone temperature. Can. J. Bot. 68:2698-2702.

Barrett, R.E., D.P. Ormrod, and R. Jung. 1978. Soil heating effects on bench grown chrysanthemum. HortScience 13:591-592.

Borowski, E., P. Hagen, and R. Moe. 1981. Stock plant irradiation and rooting of chrysanthemum cuttings in light and dark. Scientia Hort. 15:245253.

Brown, W.W. and D.P. Ormrod. 1980. Response of chrysanthemum to soil heating. Scientia Hort. 13:67-75.

Cockshull, K.E. 1976. Flower and leaf initiation by Chrysanthemummorifolium Ramat. in long days. J. Hort. Sci. 51:441-450.

de Lint, P.J.A.L. and G. Heij. 1987. Effects of day and night temperature on growth and flowering of chrysanthemum. Acta Hort. 197:53-56.

Faust, J.E. and R.D. Heins. 1993. High night temperatures do not cause poor lateral branching of chrysanthemum. HortScience 27:981-982.

Graves, W.R., M.N. Dana, and R.J. Joly. 1989. Root-zone temperature affects water status and growth of red maple. J. Amer. Soc. Hort. Sci. 114:406-410.

Graves, W.R., R.J. Joly, and M.N. Dana. 1991. Water use and growth of honey locust and treeof-heaven at high root-zone temperature. HortScience 26:1309-1312.

Heins, R.D., M.G. Karlsson, J.A. Flore, and W.H Carlson. 1986. Effects of photosynthetic rate maximization on chrysanthemum growth and development. J. Amer. Soc. Hort. Sci. 11:4246.

Heins, R.D. and H.F. Wilkins. 1979. The influence of node number, light source, and time of irradiation during darkness on lateral branching and cutting production in 'Bright Golden Anne' chrysanthemum. J. Amer. Soc. Hort. Sci. 104:265-270.

Hicklenton, P.R. 1985. Influence of different levels and timing of supplemental irradiation on pot chrysanthemum production. HortScience 20:374-376.

Holcomb, E.J., J.A. Flore, and R.D. Heins. 1988 Photosynthetic response curves for chrysanthemum grown at different PPF levels. HortScience 23:206-208

Karlsson, M.G., R.D. Heins, J.E. Erwin, R.D. Berghage, W.G. Carlson, and J.A. Biernbaum. 1989a. Temperature and photosynthetic photon 
flux influence chrysanthemum shoot development and flower initiation under short-day conditions. J. Amer. Soc. Hort. Sci. 114:158-163.

Karlsson, M.G., R.D. Heins, J.E. Erwin, and R.D. Berghage. 1989b. Development rate during four phases of chrysanthemum growth as determined by preceding and prevailing temperatures. J. Amer. Soc. Hort. Sci. 114:234-240.

Karlsson, M.G., M.P. Pritts, and R.D. Heins. 1988. Path analysis of chrysanthemum growth and development. HortScience 23:372-375.

Moe, R. 1988. Effect of stock plant environment on lateral branching and rooting. Acta Hort. 226:421-430
Moe, R. and R.D. Heins. 1990. Control of plant morphogenesis and flowering by light quality and temperature. Acta Hort. 272:81-89.

Nell, T.A., J.J. Allen, J.N. Joiner, and L.G. Albrigo. 1981. Light, fertilizer and water level effects on growth, yield, nutrient composition, and light compensation point of chrysanthemum. HortScience 16:222-223.

Nell, T.A. and J.E. Barrett. 1991. Chrysanthemum heat delay. Fla. Ornamental Growers Assn. Nwsl. May-June:4-5.

Parvups, E.V. and G. Butler. 1982. Comparative growth of chrysanthemums at different night temperatures. J. Amer. Soc. Hort. Sci. 107:600-604.
Stephanis, J.P. and R.W. Langhans. 1982. Quantum flux density studies of chrysanthemum in a controlled environment with high-pressure sodium lamps. II. Long day and short day studies. J. Amer. Soc. Hort. Sci. 107:461464.

Tsujita, M.J., D.P. Ormrod, and W.W. Craig. 1981. Soil heating and reduced night temperature effects on chrysanthemums. Can. J. Plant Sci. 61:345-350.

Whealy, C.A., T.A. Nell, and J.E. Barrett. 1987. High temperature effects on growth and development of chrysanthemum. J. Amer. Soc. Hort. Sci. 112:461-468 